\title{
Engineered PLGA-PVP/VA based formulations to produce electro-drawn fast biodegradable microneedles for labile biomolecule delivery
}

\author{
Valentina Onesto $^{1} \cdot$ Concetta Di Natale ${ }^{1,2} \cdot$ Martina Profeta $^{1} \cdot$ Paolo Antonio Netti ${ }^{1,2} \cdot$ Raffaele Vecchione $^{1,2}$
}

Received: 3 August 2020 / Accepted: 21 October 2020 / Published online: 3 November 2020

(c) The Author(s) 2020

\begin{abstract}
Biodegradable polymer microneedles (MNs) are recognized as non-toxic, safe and stable systems for advanced drug delivery and cutaneous treatments, allowing a direct intradermal delivery and in some cases a controlled release. Most of the microneedles found in the literature are fabricated by micromolding, which is a multistep thus typically costly process. Due to industrial needs, mold-free methods represent a very intriguing approach in microneedle fabrication. Electro-drawing (ED) has been recently proposed as an alternative fast, mild temperature and one-step strategy to the mold-based techniques for the fabrication of poly(lactic-co-glycolic acid) (PLGA) biodegradable MNs. In this work, taking advantage of the flexibility of the ED technology, we engineered microneedle inner microstructure by acting on the water-in-oil (W/O) precursor emulsion formulation to tune drug release profile. Particularly, to promote a faster release of the active pharmaceutical ingredient, we substituted part of PLGA with poly(1-vinylpyrrolidone-co-vinyl acetate) (PVP/VA), as compared to the PLGA alone in the matrix material. Moreover, we introduced lecithin and maltose as emulsion stabilizers. Microneedle inner structural analysis as well as collagenase entrapment efficiency, release and activity of different emulsion formulations were compared to reach an interconnected porosity MN structure, aimed at providing an efficient protein release profile. Furthermore, MN mechanical properties were examined as well as its ability to pierce the stratum corneum on a pig skin model, while the drug diffusion from the MN body was monitored in an in vitro collagen-based dermal model at selected time points.
\end{abstract}

Keywords Electro-drawing · Microneedles · Transdermal drug delivery $\cdot$ Protein release $\cdot$ Controlled release $\cdot$ PLGA

\section{Introduction}

Biocompatible microneedles (MNs) have recently gained great attention, being recognized as a pain-free and successful administration route, alternative to injection that

Electronic supplementary material The online version of this article (https://doi.org/10.1007/s40204-020-00143-2) contains supplementary material, which is available to authorized users.

Valentina Onesto

valentina.onesto@iit.it

Raffaele Vecchione

raffaele.vecchione@iit.it

1 Center for Advanced Biomaterials for Health Care, CRIB, Istituto Italiano di Tecnologia, Largo Barsanti e Matteucci 53, 80125 Naples, Italy

2 Interdisciplinary Research Center of Biomaterials, CRIB, University Federico II, P.leTecchio 80, 80125 Naples, Italy may cause pain, discomfort and avoidance by people with needle-phobia (Kim et al. 2012; Leone et al. 2017). MNs are employed for many applications ranging from vaccine delivery to biopharmaceuticals administration (Balmayor et al. 2011; Bariya et al. 2012). MN devices based on dissolvable or biodegradable polymers have been developed to overcome the drawbacks of solid microneedles, such as risks associated with tip breakages, low loading capability or difficulties in infusion systems (Lee et al. 2008; Park et al. 2005).

Most of the MN fabrication methodologies reported in literature, are based on micromolding (Jamaledin et al. 2020; Li et al. 2019; Nejad et al. 2018). Unfortunately, these moldbased techniques result in sequences of multi-step processes, temporally and economically expensive. In particular, hand solutions based on room temperature solvent casting are very time consuming (Bediz et al. 2014; Lee et al. 2008), while the use of UV treatment on photocurable polymers can inhibit the activity of the active compound encapsulated within the polymer matrix and the photoinitiator residuals 
within the final microneedles can introduce dangers in terms of toxicity (Sullivan et al. 2008).

Mold-free microneedle fabrication techniques, based on drawing lithography (Lee and Jung 2012), droplet-born air blowing (DAB) (Kim et al. 2013a, b), cyclic contact and drying process on pillars (CCDP process) (Kim et al. 2015), have been proposed as potential solutions to several of the technological limitations affecting micromolding. Nevertheless, these methods, despite being free of master fabrication processes or replica molding, are affected by limits arising from high process temperatures or features of reproducibility typically lower than the mold-based processes.

Among the mold-free techniques, electro-drawing (ED) has been recently proposed as a mild temperature, non-contact and UV-free process for the fabrication of poly(lactic-co-glycolic acid) (PLGA) polymer microneedles (Ruggiero et al. 2018; Vecchione et al. 2014). According to the ED method, microneedles are shaped in a single step starting from the deformation of drops of PLGA solution, by applying an electro-hydrodynamic (EHD) force on them.

Here, we enabled the use of ED microneedles to the encapsulation and the delivery of labile molecules such as collagenase by providing a faster degradable formulation as compared to PLGA. Indeed, as compared to the previous work, the focus of this work is on the formulation which provides a completely different microstructure, mainly based on a continuous porosity that guaranties drug release in a time-frame of few hours.

Collagenase is a zinc-dependent metallo-proteinases able to degrade with a high specificity collagen substrates, playing a key role in the modulation of inflammation disorders, chronic wounds, ulcers or removal of cellular debris (Di Pasquale et al. 2019). The recent combination of collagen-lytic activity of collagenase with the wound healing properties of hyaluronic acid led to the production of a safe and active pharmaceutical formulation for the topical treatment of wounds, HYALO4 STARTMET (Di Pasquale et al. 2019). Unfortunately, being a protease, collagenase suffers of instability in physiological environment; in particular, it has been reported that it has a stability of maximum $8 \mathrm{~h}$ when it is stored at $4{ }^{\circ} \mathrm{C}$ or $24-48$ months when storage temperatures range between -20 and $-80{ }^{\circ} \mathrm{C}$ (Vaccaro et al. 2017). Starting from these considerations, our idea was to encapsulate it within a W/O single emulsion to have a polymeric shell as protection. Polymer-encapsulated drugs are in general more effective than their freely delivered counterparts, since polymer-loaded drugs are protected from degradation (McCall and Sirianni 2013). This protection provides a longer biological half-life and a potentially improved efficacy with reduced systemic side effects. However, once applied in vivo, proteins are subjected to a number of stability constraints due to the fact that being the delivery system in a wet condition, protein starts to be exposed to water even before being released (Wu and Jin 2008). For these reasons, the aim of this work is to shorten the prolonged release in a time window of few hours, reducing in this way the drug degradation over time (Kamaly et al. 2016). This has been possible since $\mathrm{W} / \mathrm{O}$ emulsions can be easily controlled in their porosity degree during the fabrication process, which is a fundamental aspect in pharmaceutical formulations because the drug release strictly depends on the porosity of the material. Additionally, we optimized the emulsion formulation substituting part of PLGA with a copolymer poly(1-vinylpyrrolidone-co-vinyl acetate) (PVP/VA) as a continuous phase to accelerate polymer matrix dissolution. A relatively fast release is also useful to reach higher dosages as compared to slower release systems. For instance, in the case of collagenase, being it a labile molecule, low dosages may not achieve an in vivo therapeutic effect because of its serum inhibition (Badalamente and Hurst 2007).

Herein, different emulsion formulations were tested varying the PLGA-PVP/VA ratio as well as the amount and composition of the water phase. The results demonstrated that the addition of PVP/VA modifies the MN inner microstructure leading to the formation of interconnected porosity. The addition of maltose in the water phase helped in prolonging the W/O emulsion stability (Esposito et al. 2016). Microneedle morphology, inner structure and mechanical properties were also investigated. Collagenase entrapment efficiency, release and activity data were analyzed by fluorescence and UV confirming its functionality upon microneedle production process.

Moreover, MN ability to pierce the stratum corneum was confirmed on a pig skin model and the drug diffusion from their body was monitored in an in vitro dermal model at selected time points, such as $30 \mathrm{~min}, 2 \mathrm{~h}$ and $24 \mathrm{~h}$.

Thanks to the ability in easily engineering the precursor emulsion formulation, our electro-drawn microneedles, could represent a new road in the pharmaceutical market of collagen-related pathologies.

\section{Materials and methods}

\section{Materials}

Collagenase (produced from Vibrio alginolyticusby Fidia Farmaceutici S.p.A.Noto, Siracusa, Italy, using a non-pathogenic aerobic bacterium (V. alginolyticus) by an aerobic fermentation process which produces a very purified enzyme lacking in microbial impurities (Vaccaro et al. 2017). Pyroelectric substrates were purchased from Altechna (LithiumTantalate $\mathrm{LiTaO}_{3}$ optical grade wafers, z-cut, $0.5 \mathrm{~mm}$ thick, double side polished).

Positive AZ®ECI 3012 photoresist and AZ 351 B developer were purchased from Microchemicals. 2-Propanol and 
acetone were both provided by Sigma-Aldrich. Titanium pellets (purity 99.95\%) for metal deposition were purchased from KurtJ. Lesker Company, while wrapping wires and silver conductive paint employed for circuit connections were provided by RS Components. Polymethyl methacrylate (PMMA) sheets, with thickness ranging from 1 to $5 \mathrm{~mm}$, were provided by Goodfellow. Further, Dow Corning Sylgard 184 Silicone elastomer, joint to its curing agent, was used for the fabrication of arrays of pillars and deposition vessels.

Poly(lactic-co-glycolic acid) with molecular weight in the range 38,000-54,000 Da (PLGA or RESOMER $® R G$ $504 \mathrm{H}$ ), was purchased from Evonik Industries. Poly(1vinylpyrrolidone-co-vinyl acetate) solution (molecular weight $13,000,50 \mathrm{wt} \%$ in isopropanol) was purchased from Sigma-Aldrich. $24 \mathrm{~h}$ before usage isopropanol was left to evaporate and solidified PVP/VA was weighed as biopolymer for microneedles. Dimethyl carbonate (DMC, $\geq 99 \%$ ) used as solvent for PLGA and D-(+)-maltose monohydrate (BioUltra, $\geq 99.0 \%$, C.A.S. 6363-53-7) were purchased by Sigma-Aldrich. Egg lecithin (Lipoid E 80) was purchased from Lipoid (Ludwigshafen, Germany).

\section{Collagenase functionalization}

Collagenase was covalently conjugated to Atto-488-maleimide using a previously reported procedure (Hermanson 2013). Briefly, a solution of $0.43 \mathrm{mg} / \mathrm{mL}$ of the enzyme (tris(hydroxymethyl)aminomethane (TRIS) buffer, $\mathrm{pH} 7.1$ ) was mixed with a 20 -fold molar excess of reactive dye for $1 \mathrm{~h}$ at $25{ }^{\circ} \mathrm{C}$ under magnetic stirring. Unbound dye was removed using a $3 \mathrm{kDa}$ molecular weight cut-off Vivaspin 6 centrifuge filter. The correct enzyme-dye conjugation was validated by the UV-vis technique, as reported in our previous paper (Battisti et al. 2019).

\section{Collagenase-488 entrapment efficiency (\%ฤ) and release}

The $\% \eta$ of collagenase-Atto 488 was measured by fluorescence as already reported using an EnSpire R Multimode Plate Reader and following the signal of functionalized collagenase at $520 \mathrm{~nm}$ (Battisti et al. 2019). To summarize, three patches of each configuration of microneedles were dissolved in a mixture of dimethyl sulphoxide (DMSO)/ sodium dodecyl sulfate (SDS)/ sodium hydroxide $(\mathrm{NaOH})$ for $30 \mathrm{~min}$ at room temperature. The quantification was performed using a titration curve of the free collagenase in the same conditions (Figure S1). As to the release, three patches of each configuration were suspended in $1.5 \mathrm{~mL}$ of TRIS buffer $\mathrm{pH} 7.1$ and incubated at $37{ }^{\circ} \mathrm{C}$ and at $500 \mathrm{rpm}$. From a time period of $30 \mathrm{~min}$ until $24 \mathrm{~h}, 1 \mathrm{~mL}$ of PBS was removed (at the equal time the patches were refreshed with the same amount of PBS and analyzed by fluorescence. Calibration curves of free enzymes were prepared in TRIS buffer (Figure S2).

\section{Collagenase activity}

To validate the activity of enzyme inside microneedles, "collagenase chromophore substrate" assay was performed (Wuensch and Heidrich 1963). In particular, two patches of microneedles of each formulation were put in contact for $15 \mathrm{~min}$ with the collagenase chromophore substrate and the cleaved peptide was analyzed by UV-vis at $320 \mathrm{~nm}$ as described by Wuensch and Heidrich (1963). Data were normalized with respect to the amount of collagenase contained into each MN patch on the basis of the final amount of the obtained polymer.

\section{Integrated device fabrication}

The fabrication of the integrated device on the pyroelectric crystal was carried out as described in (Ruggiero et al. 2018). Briefly, a thin layer of photoresist was deposited onto the crystal and spin coated (Laurell Technologies Corporation) for $60 \mathrm{~s}$ at $3000 \mathrm{rpm}$. To avoid electrical discharges due to the pyroelectricity, the soft-bake step was performed following a temperature ramp of $1 \mathrm{~min}$ and $30 \mathrm{~s}$, from room temperature up to $90{ }^{\circ} \mathrm{C}$. The sample was then gradually brought again to room temperature. Selective exposure was induced by a direct laser writer system (DWL 66 fs, Heidelberg Instruments Mikrotechnik) by setting, as exposure parameters, $60 \%$ for the beam intensity and $30 \%$ for the focus. The same thermal ramp of the soft-bake step was followed for the post-exposure bake treatment. The sample was then developed for $60 \mathrm{~s}$ and cleaned in deionized water. After the development, a titanium thin layer (having a thickness of $200 \mathrm{~nm}$ ) was deposited onto the crystal using a thermal evaporator (Tecnoservice) equipped with a thickness controller (Inficon). Then, a lift off process of 15 min was carried out by immersing the sample in pure acetone within a sonicating bath, to obtain the final desired metallic pattern. Finally, the sample was cleaned and dried with nitrogen. Titanium thickness was measured by performing a profiler analysis (VeecoDektak 150). The fabricated device was then finalized by welding connection wires.

\section{Fabrication of the arrays of pillars and of deposition vessels}

Polydimethylsiloxane (PDMS) arrays of $4 \times 4$ cylindrical pillars characterized by a center-center distance of $600 \mu \mathrm{m}$, diameter of $300 \mu \mathrm{m}$ and height of $300 \mu \mathrm{m}$, were fabricated by replica molding onto a poly(methyl methacrylate) (PMMA) substrate. PDMS was chosen as an example of flexible 
support to show the ability to directly obtain microneedles onto a flexible substrate which is a potential advantage as compared to other manufacturing techniques where the microneedles are connected to each other and therefore they cannot be thought for a conformal application of the patch on the skin.

Square PDMS vessels, used as tanks to deposit the emulsion (Fig. 1a), with edge of $1 \mathrm{~cm}$ and depth of $3 \mathrm{~mm}$ were obtained with the same method.

Briefly, PMMA molds reproducing the negative of the desired geometries (of the pillars or of the vessel) were fabricated by micromachining (Minitech CNC Mini-Mill). The obtained PMMA master was then cleaned from milling process debris by sonication in water for $10 \mathrm{~min}$ and dried with compressed air. PDMS elastomer was mixed with the curing agent in the 10:1 w/w ratio. Air bubbles arising from the mixing process were removed by putting the mixture in a vacuum chamber for $30 \mathrm{~min}$. The PMMA master was filled with the mixture, which was degassed again for further $20 \mathrm{~min}$. A $45 \mathrm{~min}$ thermal treatment at $80{ }^{\circ} \mathrm{C}$ was used to cure the PDMS. The PDMS was finally peeled off from the PMMA master.

\section{Preparation of the emulsion}

PLGA and/or PVP/VA were dissolved in DMC as a nontoxic and environmentally friendly solvent, in percentages ranging from 20 to $40 \% \mathrm{w} / \mathrm{v}$ (Table1). This represents the continuous phase of the W/O emulsions. Two different water phases were tested in our emulsions. In particular, the first
A Deposition of drops of emulsion on PDMS pillars by microcontact
B Electro-drawing

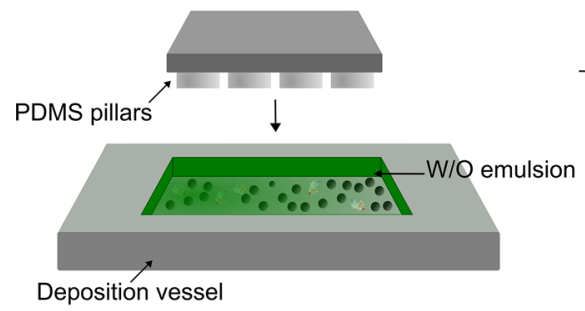

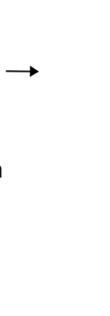
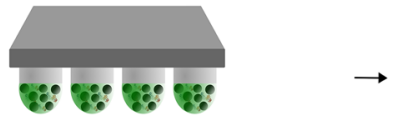

pattern

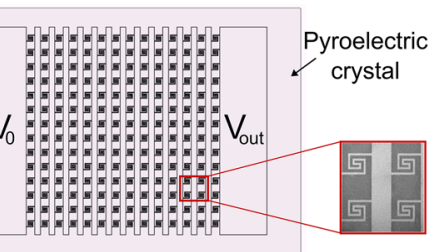

C Microneedles
Fig. 1 a Water-in-oil emulsion containing collagenase in the water phase is deposited within a vessel. Then, PDMS pillars, moved by motorized stages, come in contact with the emulsion forming drops. b A voltage is applied to the titanium circuitry patterned on the pyroelectric crystal and $\mathbf{c}$ microneedles are shaped by the action of the uniform electric field
Table 1 Different water-inoil emulsion formulations employed to fabricate microneedles by electrodrawing and corresponding collagenase entrapment efficiencies and releases after $3 \mathrm{~h}$

\begin{tabular}{lllll}
\hline Case & Oil phase & $\begin{array}{l}\text { Water phase (with } \\
\text { collagenase) }\end{array}$ & $\begin{array}{l}\text { Entrapment\% } \\
\text { Release } \\
\text { after 3 h } \\
\%\end{array}$ \\
\hline c1 & PLGA 200 mg in 1 mL DMC & $200 \mu \mathrm{L} \mathrm{AB}$ & 100 & 2 \\
c2 & PLGA 200 mg in 1 mL DMC & $200 \mu \mathrm{L} \mathrm{LM}+\mathrm{AB}$ & 89.9 & 7.4 \\
c3 & PLGA 200 mg in 1 mL DMC & $200 \mu \mathrm{L} \mathrm{LM}$ & 74.5 & 6.5 \\
c4 & (PLGA 100 mg + PVP/VA 100 mg) in 1 mL DMC & $200 \mu \mathrm{L} \mathrm{AB}$ & 100 & 3.2 \\
c5 & (PLGA 100 mg + PVP/VA 100 mg) in 1 mL DMC & $200 \mu \mathrm{L} \mathrm{LM} \mathrm{+} \mathrm{AB}$ & 59.7 & 4.9 \\
c6 & (PLGA 100 mg + PVP/VA 100 mg) in 1 mL DMC & $200 \mu \mathrm{L} \mathrm{LM}$ & 67.2 & 10.4 \\
c7 & (PLGA 50 mg + PVP/VA 150 mg) in 1 mL DMC & $200 \mu \mathrm{L} \mathrm{LM}$ & 69 & 10.1 \\
c8 & PVP/VA 200 mg in 1 mL DMC & $200 \mu \mathrm{L} \mathrm{LM}$ & 43.6 & 20.6 \\
c9 & (PLGA 50 mg + PVP/VA 150 mg) in 1 mL DMC & $250 \mu \mathrm{L} \mathrm{LM}$ & 48.18 & 27.1 \\
c10 & (PLGA 50 mg + PVP/VA 150 mg) in 1 mL DMC & $200 \mu \mathrm{L} \mathrm{LM}$ & 68.19 & 13.35 \\
c11 & (PLGA 50 mg + PVP/VA 150 mg) in 1 mL DMC & $350 \mu \mathrm{L} \mathrm{LM}$ & 59.3 & 23.8 \\
c12 & (PLGA 50 mg + PVP/VA 150 mg) in 1 mL DMC & $500 \mu \mathrm{L} \mathrm{LM}$ & 72.8 & 24.3 \\
c13 & PVP/VA 400 mg in 1 mL DMC & $250 \mu \mathrm{L} \mathrm{LM}$ & 57.3 & 26.9 \\
c14 & PVP/VA 300 mg in 1 mL DMC & $250 \mu \mathrm{L} \mathrm{LM}$ & 56.1 & 21.9 \\
\hline
\end{tabular}


set of samples $(\mathrm{AB})$ were produced with ammonium bicarbonate $(7.5 \% \mathrm{w} / \mathrm{w}$ respect to polymer) dissolved in TRIS. In the other set of samples (LM), $180 \mathrm{mg} / \mathrm{mL}$ of lecithin were dissolved in TRIS; maltose was subsequently added until saturation (corresponding to $360 \mathrm{mg} / \mathrm{mL}$ ). In both the water phases, collagenase-Atto 488 was added in a concentration of $188 \mu \mathrm{g} / \mathrm{mL}$. The water phase was added to the oil phase in different amounts (Table 1) and emulsified using an immersion emulsifier (Ultra-turrax, IKA T-25 ULTRATURRAX Digital High-Speed Homogenizer Systems) for $1 \mathrm{~min}$ at 15,000 rpm, keeping samples in a nice bath to preserve protein activity.

\section{Fabrication of the microneedles}

A volume of $0.25 \mathrm{~mL}$ of polymer emulsion was deposited by syringe within the PDMS vessel. To obtain controlled volume drops $(0.01 \mu \mathrm{L})$ of emulsion on the top of the pillars, the PDMS pillars in upside-down position on a motorized stage (Thorlabs) were positioned $1 \mathrm{~mm}$ down the top of the vessel, coming in contact with the emulsion (Fig. 1a). Pillars are then brought, through the motorized stages, to a distance from the pyroelectric crystal equal to the desired final microneedle length and the electro-drawing of drops in microneedles was obtained by the action of the uniform electric field generated from the pyroelectric effect, upon the voltage was applied to the circuitry (Fig. $1 \mathrm{~b}$ and c). The evolution of the microneedle shape was monitored by a lateral camera (Dino Lite). The microneedle shape was consolidated for $5 \mathrm{~min}$ (for PLGA MNs) or $10 \mathrm{~min}$ (for MNs containing PVP/VA) under the action of the electric field, after having increased the distance of $1 \mathrm{~cm}$ from the previous position. To be sure of the storage conditions, we kept our microneedles in boxes containing de-drying agents.

\section{Morphological analysis of MN inner microstructure}

To investigate chromophore distribution inside the MNs, MNs were analyzed by confocal microscopy (Leica Microsystems TCS SP5 II, Germany) at $488 \mathrm{~nm}$ using a $20 \times$ microscope objective. All images were acquired with a resolution of $1024 \times 1024$ pixels. Sections of matrices were prepared using Leica CryoUltra Microtome EM-FC7UC7. Thin strips were incorporated in polydimethylsiloxane (PDMS), cured for $24 \mathrm{~h}$ at room temperature, and then frozen at $-140{ }^{\circ} \mathrm{C}$. Finally, they were sectioned at a thickness of $5 \mu \mathrm{m}$. Pictures of porosity were taken using field emission SEM (Ultra plus Zeiss, Jena, Germany imposing $5 \mathrm{kV}$ of voltage (EHT), after sputter coating of the samples with a $20 \mathrm{~nm}$ thick gold layer.

Acquired SEM images of MN sections were analyzed using ImageJ (V. 1.52p, Wayne Rasband, National Institutes of Health, Bethesda, MD,USA) to conduct a semi-quantitative analysis of pore sizes and porosity percentages.

Pores were identified selecting regions of interest of the SEM images (Figure S3) and, subsequently, the areas of all pores were summed and related to the total area of the considered image, according to Eq. 1:

Porosity $(\%)=\frac{\sum A_{\text {pore }}}{A_{\text {tot }}} 100$

where $A_{\text {pore }}$ is the value of the area of each pore, and $A_{\text {tot }}$ is the total area of the acquired image. To quantify porosity (\%), 9 slices for each different type of $\mathrm{MN}$ formulation (three different slices belonging to three different samples) were considered.

\section{Mechanical failure test}

To measure the force a microneedle can withstand before mechanical failure under an axial load, a displacement force test station (Instron 5943L4717), equipped with two metallic plates was used. A compressive method was created and load vs displacement curves were generated by measuring force and displacement at a rate of $0.1 \mathrm{~mm} / \mathrm{s}$. Images of the microneedle before and after the compressive test were acquired using a stereomicroscope (Olympus SZ61) to determine the mode of failure.

\section{Microneedle insertion assessment into Cadaver pig skin}

To determine microneedle ability to pierce the stratum corneum, these were inserted into porcine cadaver skin. Single MN having height $600 \mu \mathrm{m}$ and base $300 \mu \mathrm{m}$ was electrodrawn on a PMMA cylindrical pillar. PMMA pillars were chosen to test the MN capability of piercing the stratum corneum, independently from its support, having PMMA a higher elastic modulus. The pillar was fabricated employing a micromilling machine (Minitech CNC Mini-Mill) and it had a diameter of $300 \mu \mathrm{m}$ and a height of $300 \mu \mathrm{m}$.

Excised porcine skin was shaved using a razor and the skin's subcutaneous fat was removed using a scalpel. The processed skin was cut into pieces and taken overnight in a phosphate buffered saline/ penicillin-streptomycin (PBS/ PS) $(1: 1 \mathrm{v} / \mathrm{v})$ solution at $4{ }^{\circ} \mathrm{C}$.

The surface of the skin was dried with laboratory filter papers (Whatman ${ }^{\circledR}$ ) and the microneedles were inserted by thumb into the skin for $3 \mathrm{~min}$. After that, microneedles were gently removed from the skin. Both the microneedles and the porcine skin were imaged by means of a stereomicroscope (Leica EM UC 7) before and after the insertion assessment. Moreover, a hydrophobic dye, the methylene blue solution (MB) (Sigma-Aldrich), was placed on the skin for $1 \mathrm{~h}$ to 
stain the microchannels created from the microneedles penetration. The skin was then washed thoroughly in PBS to remove the excess dye from the surface. Finally, the skin was again imaged using a stereomicroscope to identify the hole left by the microneedle insertion (Nguyen et al. 2018) and the image of a MB-treated piece of skin was also taken as negative control.

\section{In vitro dermis equivalent: preparation and characterization}

The 3D in vitro dermis equivalent model was set up embedding human dermal fibroblast (HDF) cells in a collagen matrix. Cells were cultured with complete medium, composed of Eagle's minimal essential medium (EMEM) supplemented with $20 \%$ FBS, $1 \%$ glutamine, $1 \%$ non-essential amminoacids and $100 \mathrm{U} / \mathrm{mL}$ penicillin, $100 \mathrm{mg} / \mathrm{mL}$ streptomycin. The cells were maintained in $100 \mathrm{~mm}$ diameter cell culture dishes in a humidified controlled atmosphere at $37^{\circ} \mathrm{C}$ and $5 \% \mathrm{CO}_{2}$. The medium was changed every $2-3$ days. Collagen gels were prepared using rat-tail collagen solution (ibidi ${ }^{\circledR}$ ) and reconstituted according to the manufacturer's protocol. HDF cells of $6 \times 10^{4}$ were suspended in $300 \mu \mathrm{L}$ of $4 \mathrm{mg} / \mathrm{mL}$ collagen solution and poured into a Millicell ${ }^{\circledR}$ (Cell culture inserts, Millipore). The system was then incubated at $37{ }^{\circ} \mathrm{C}$ for $30 \mathrm{~min}$ to allow collagen fibrillogenesis and, afterwards, fresh cell culture medium was added to the gel. Finally, cells were incubated with DRAQ5 (Abcam) diluted 1:1000 in PBS for 30 min at RT for cell nuclei staining, to characterize the model by means of confocal microscopy (Leica Microsystems TCS SP5 II, Germany). Images were acquired with a $25 \times$ water immersion objective and a resolution of $1024 \times 1024$ pixels.

\section{Release test into the in vitro dermis equivalent model}

To determine microneedles ability to penetrate into the dermis and release their cargo, microneedles were inserted into the collagen model and the fluorescent signal of the encapsulated enzyme was followed at different time points (i.e. $30 \mathrm{~min}, 2 \mathrm{~h}$, and $24 \mathrm{~h}$ ). The results were obtained by confocal microscopy (Leica Microsystems TCS SP5 II, Germany) with a $10 \times$ water immersion objective and images were acquired with a resolution of $1024 \times 1024$ pixels.

\section{Results}

\section{Fabrication of microneedles and analysis of their inner microstructure.}

We tested different emulsion formulations, finalized to the formation of microneedles by the electro-drawing technique. Electro-drawing is a mask-less and mold-less 3D lithography process by which microneedles are fabricated under the action of electro-hydrodynamic pressure induced by a pyroelectric effect (Ruggiero et al. 2018; Vecchione et al. 2014), Fig. 1b and c. An optical image of a PVP/ $\mathrm{VA}+$ PLGA electro-drawn microneedle morphology is shown in Fig. 2a.

Microneedle porosity represents a big issue in drug delivery applications since it is related to the amount of drug that can be loaded inside the polymeric matrix, and as a consequence, successively released in the body. With the electro-drawing technology, the microneedle inner microstructure can be flexibly and easily engineered playing with the precursor water-in-oil formulation, to tune drug release profile. In particular, to obtain a fast protein release kinetics, we studied 14 different emulsion formulations, analyzing consequent $\mathrm{MN}$ porous structure as well as the entrapment efficiency, release profiles and activity of collagenase (Table 1). We started from emulsions containing PLGA polymer 50: $50(20 \% \mathrm{w} / \mathrm{v})$ dissolved in $1 \mathrm{~mL}$ of dimethyl carbonate (DMC) and $200 \mu \mathrm{L}$ of collagenase- 488 with the addition of $7.5 \%$ of ammonium bicarbonate (Table 1, case c1), which was previously used for the fabrication of porous microparticles for drug delivery (Di Natale et al. 2020). Needle microstructures were observed by confocal microscopy and ammonium bicarbonate showed to produce low size pores, with diameters of $1.5 \pm 0.6 \mu \mathrm{m}$ (Fig. 2b, Figure S3). Therefore, the water solution of ammonium bicarbonate was replaced by $200 \mu \mathrm{L}$ of D-maltose monohydrate and lecithin, dissolved in the protein buffer (TRIS buffer, $\mathrm{pH}$ 7.1). This solution allowed the formation of internal microstructures expressing higher pore sizes of mean diameter of $15 \pm 2.7 \mu \mathrm{m}$ (Fig. 2c). Moreover, the presence of maltose limited the phenomena of coalescence and phase separation and the emulsion was more stable over time.

Once defined the water part of the emulsion, we started to study the nature of the polymeric matrix. Because the PLGA used for our study degrades in vivo in a couple of weeks (Ma et al. 2011), we combined it with poly(1vinylpyrrolidone-co-vinyl acetate) copolymer in different ratios (Table 1). As we can see from Fig. 2d, emulsions with PVP/VA in the oil phase and lecithin and maltose in the water phase, with the formation of microneedles with interconnected pores, evenly distributed throughout the 

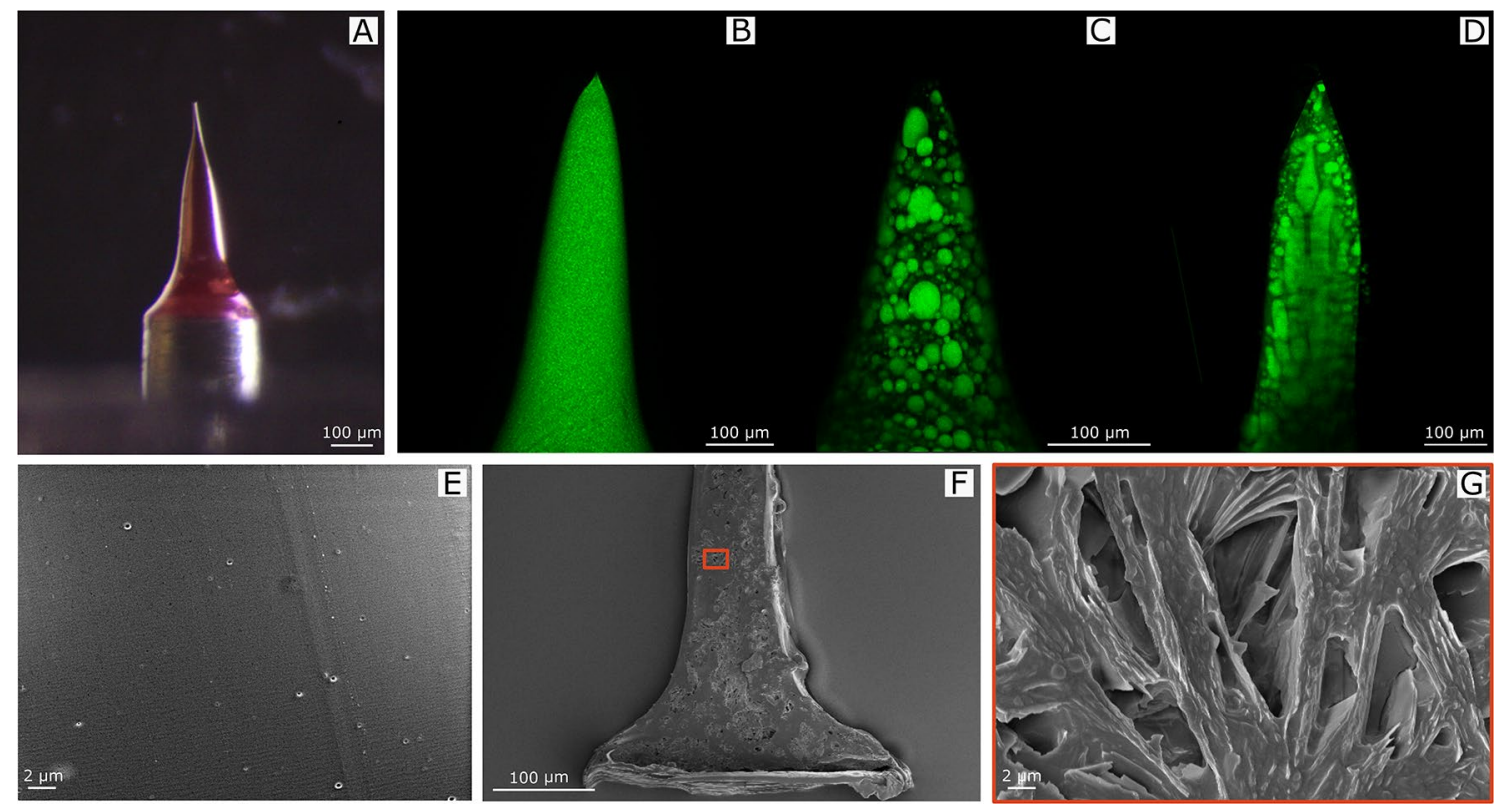

Fig. 2 a Optical image of an electro-drawn microneedle made of PVP/VA + PLGA. Confocal microscopy images of collagenase-488 entrapped in electro-drawn MNs made of b $200 \mathrm{mg}$ PLGA in $1 \mathrm{~mL}$ DMC with $200 \mu \mathrm{L}$ of water solution ofammonium bicarbonate $(7.5 \%$ $\mathrm{w} / \mathrm{w}$ respect to polymer) dissolved in TRIS, c $200 \mathrm{mg}$ PLGA in $1 \mathrm{~mL}$ DMC with $200 \mu \mathrm{L}$ of water solution containing lecithin $(180 \mathrm{mg} /$ $\mathrm{mL}$ in TRIS) and maltose (360 mg/mL in TRIS), d $150 \mathrm{mg}$ PVP/

length of the cone. Different types of PVP are reported to be able to produce high-porosity structures, such as cross-linked PVP, homopolymers (with different molecular weights) or copolymers (Malik et al. 2019). Likewise, an enhancement of porosity into biomedical formulations has been reported using PVP as additive (Franco and De Marco 2020). Moreover, replacing some of the hygroscopic VP repeat units with hydrophobic repeat units of $\mathrm{VA}$ as is the case of PVP/VA copolymers (PVP/VA) a greater physical stability of biomedical structures can be obtained (Prudic et al. 2014).

The inner microstructure was even characterized by SEM microscopy of longitudinal sections, indicating confocal microscopy observations and an evidence of the interconnected pores, which represents an improvement as compared to the starting formulation case (Fig. 2e-g). Moreover, the porosity percentage, expressed as the sum of the areas of all pores with respect to the total area (Methods 2.9), was of $41 \%$ against the $0.4 \%$ of the starting formulation (Figure S3).

Final considerations are related to ED fabrication and prefabrication aspects of the MNs. In general, W/O emulsions containing PVP/VA in the continuous phase needed, as a microneedle was just electro-drawn, a 10 min shape consolidation time under the action of the electric field, higher compared to the 5 min of the sole PLGA, but still suitable considering that ED is a single step fabrication process. In
VA + $50 \mathrm{mg}$ PLGA in $1 \mathrm{~mL}$ DMC with $250 \mu \mathrm{L}$ of water solution containing lecithin $(180 \mathrm{mg} / \mathrm{mL}$ in TRIS $)$ and maltose $(360 \mathrm{mg} / \mathrm{mL}$ in TRIS). SEM microscopy of MN longitudinal sections showing e the closed porosity of PLGA with ammonium bicarbonate MNs and $\mathbf{f}, \mathbf{g}$ the interconnected structures of PVP/VA + PLGA with lecithin and maltose MNs

some cases (c8) emulsion density was very low preventing the microneedle shaping through electric field application. when PLGA was totally absent (c13, c14), MN formation was possible but it was difficult to control the shape. Even if water phase densification by the addition of maltose limited phenomena of coalescence and phase separation, in other cases $(\mathrm{c} 11, \mathrm{c} 12)$ the typical water-in-oil (W/O) emulsion instability was encountered: after 15 min we tested stratification of water phase in the upper part of the emulsions, because of the very high water phase amount in these formulations, tested to increase the release of the protein.

\section{Characterization of the entrapment of collagenase in the microneedles as a consequence of MN inner microstructure}

To evaluate the content of the enzyme into all formulations, we conjugated the ATTO 488 to the cysteine side chain of the protein, as reported in the Materials and Methods. The correct conjugation was evaluated by UV-vis recording the spectrum of the enzyme after the functionalization and purification reactions. Figure 3 confirmed that reaction was occurred, showing two peaks: one at $500 \mathrm{~nm}$ that is typical of the dye and the other at $280 \mathrm{~nm}$ associated to the protein. Afterward, using fluorescence (Figure S4), we calculated the $\% \eta$ of the enzyme for each formulation. The results 


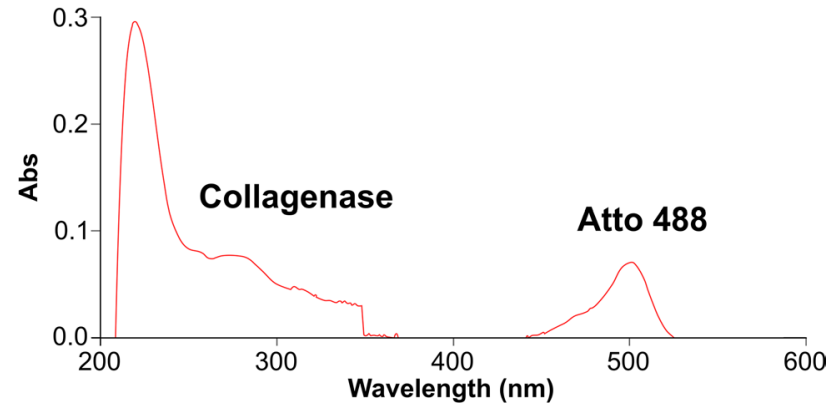

Fig. 3 UV-vis of collagenase-Atto 488 functionalization

reported in Table 1, showed that the encapsulation efficiency of collagenase- 488 in the microneedles was major of $40 \%$ for all compositions, reaching $100 \%$ for $\mathrm{c} 1$. This result was expected as in electro-drawing the emulsion containing the collagenase is directly shaped to form microneedles limiting the protein loss. Nevertheless, the addition of agents such as lecithin and maltose, seems to reduce the encapsulation efficiency which is probably due to a decrease in the $\mathrm{pH}$ of the emulsions (calculated to be equal to 5.01) becoming closer to the $\mathrm{pH}$ of the protein (4.5) with possible generation of protein aggregation phenomena.

\section{Characterization of the in vitro release of collagenase loaded microneedles}

In vitro release profiles of microneedles containing collagenase were performed as reported in the Materials and Methods section. As shown in Fig. 4, after 24 h, PLGA $50 \mathrm{mg}+\mathrm{PVP} / \mathrm{VA}$ $150 \mathrm{mg}+\mathrm{LM}$ (c9) and PVP/VA $400 \mathrm{mg}+\mathrm{LM}$ (c13) formulations released $27 \%$ of the enzyme, producing the most efficient enzyme diffusions. Contrary, the less efficient enzyme releases were obtained from PLGA with $\mathrm{AB} / \mathrm{AB}+\mathrm{LM}(\mathrm{c} 1$, c2, c3) or from PLGA-PVP/VA with AB/AB + LM (c4, c5)

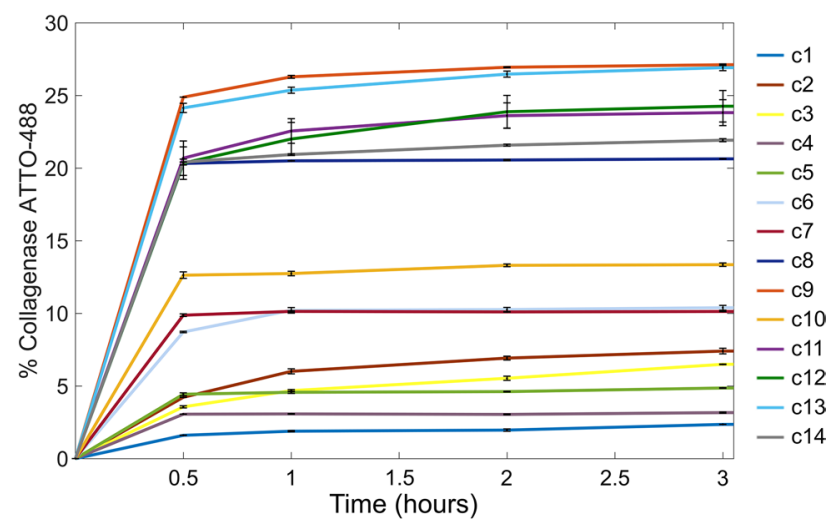

Fig. 4 In vitro release of collagenase-Atto 488 from different microneedle formulations, in TRIS buffer $\mathrm{pH}$ 7.1. Time periods from 0 to $24 \mathrm{~h}$ using a minor amount of polymer or equivalent amount of PLGA/PVPVA. These data are coherent with confocal and SEM characterization of the microneedles which revealed the formation of internal microstructures with high porosity for formulations where LM were added. Moreover, the increase of the amount of PVP/PVA in the oil phase led faster collagenase release, confirming the interconnected porosity and the upgrading of the starting formulation case. Moreover, all experiments showed a plateau level at about $3 \mathrm{~h}$ and this is due to the fact that the release becomes so slow that collagenase degrades before accumulating at a critical detectable concentration. This consideration was corroborated by the data obtained incubating collagenase at $37{ }^{\circ} \mathrm{C}$ at 3 different concentrations $(22 \mu \mathrm{g} / \mathrm{mL}, 0.22 \mu \mathrm{g} / \mathrm{mL}$ and $0.022 \mu \mathrm{g} / \mathrm{mL})$ and for different time periods (from 0 to $4 \mathrm{~h}$ ). As shown in Figure S5 $\mathrm{A}-\mathrm{B}$, protein fluorescent signal started to decrease after $3 \mathrm{~h}$ due to the exposure over time to the aqueous environment which initiates degradation phenomena.

\section{Characterization of the activity of collagenase in the microneedles}

To validate the activity of the enzyme inside the microneedles, we selected the three best formulations derived by the entrapment and in vitro release results (c3, c9, c13). Using the assay reported in the Materials and Method section, three patches of the designated formulations were dissolved in TRIS buffer and incubated at $37^{\circ} \mathrm{C}$ for 15 min together with the synthetic collagenase substrate. The peptide cleaved after this time period was analyzed by UV-vis following the signal at $320 \mathrm{~nm}$ (Figure S6- c3_a, c3_b, c9_a, c9_b, c13_a and c13_b). Empty microneedles and standard collagenase solution were used as negative and positive controls, respectively (Figure S6- blank and STD). As revealed in Table 2, the $\mathrm{c} 3$ formulation showed the highest percentage of the activity (70.8\%), while the $\mathrm{c} 9$ and c13 displayed only $37.8 \%$ and the $18.3 \%$ respectively. Even if for formulation $\mathrm{c} 3$ collagenase stored a high biological activity after the $\mathrm{MN}$ production process, due to the low porosity of the $\mathrm{MN}$ structure, the protein remains embedded inside the PLGA phase and this allows a release of only $6.5 \%$ after $3 \mathrm{~h}$. On the contrary, c13 maintains good release and entrapment efficiency, but it shows the lowest biological activity. Moreover, as discussed above, it was difficult to control the MN shape during the electro-drawing of PLGA-free (c13, c14) formulations. Lastly, case $\mathrm{c} 9$ shows intermediate percentages of activity as well as of entrapment and the highest collagenase release

Table 2 Activity percentage of collagenase inside microneedles

\begin{tabular}{ll}
\hline Formulation name & Activity \% \\
\hline c3 & $70.8 \pm 0.4$ \\
c9 & $37.8 \pm 7.1$ \\
c13 & $18.3 \pm 1.8$ \\
\hline
\end{tabular}


$(27 \%)$ after $3 \mathrm{~h}$, because of the interconnected porosity of the inner microstructure. For these reasons, c9 was chosen as the most suitable emulsion preparation for electro-drawn MNs.

\section{Mechanical failure test}

The force required to cause needle failure by axial loading was measured to determine if microneedles are strong enough to pierce the skin without breaking. Data show (Fig. 5c) that upon needle failure, the force suddenly fall and the maximum force applied immediately before the decline was interpreted as the force of needle failure $(0.123 \mathrm{~N} /$ needle). These results are in accordance with the work by Park et al. where their microneedles are able to indent the skin with an insertion force over a range of $0.10-0.22 \mathrm{~N} /$ needle (Park et al. 2006, 2005).

Moreover, as shown in Fig. 5a and b, the single needle was examined using a stereomicroscope before and after the failure test to show the deformation due to the compressive test.

Fig. 5 Light micrograph of a single microneedle (height $600 \mu \mathrm{m}$; base $300 \mu \mathrm{m}$ ) before (a) and after (b) an axial failure test; scale bar $300 \mu \mathrm{m}$. c Failure behavior of the microneedle under an axial load. Needle failure is identified by a sudden drop in force

\section{Microneedle insertion assessment into Cadaver pig skin}

To test the microneedle ability to pierce the stratum corneum, single MNs on PMMA cylindrical pillars were prepared and inserted by thumb into a piece of cadaver pig skin and then removed after $3 \mathrm{~min}$. Images of the skin before and after the needle insertion were acquired. After that, the MB-solution was applied for $1 \mathrm{~h}$ on the pierced skin. MB is a hydrophobic dye able to diffuse into the disrupted areas of the skin but not into the intact and lipophilic vicinity (Nguyen et al. 2018). Also in this case the skin was examined by light microscopy to image the piercing site.

Image Fig. 6 contains representative optical photomicrographs, which show the skin before (Fig. 6a) and after indentation (Fig. 6c, d) stained with MB and an untreated piece of skin stained with $\mathrm{MB}$ as negative control (Fig. 6b). In particular, images Fig. 6c, d show the resulting blue dot on the epidermis. This indicates that the
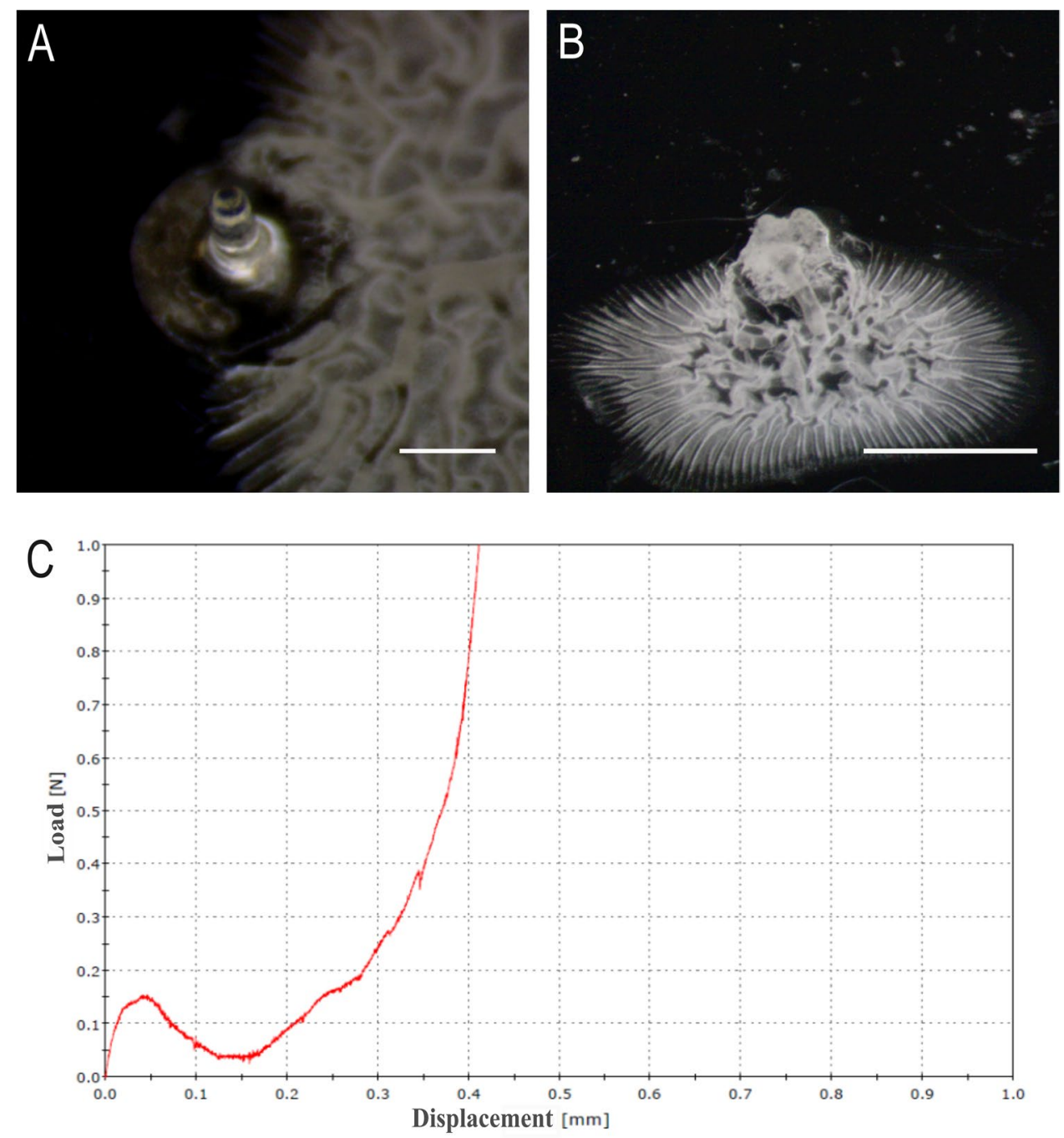
Fig. 6 Microneedle insertion assessment into Cadaver pig skin. a Skin before insertion, $\mathbf{b}$ MB-treated skin with no insertion, $\mathbf{c}$ and $\mathbf{d}$ MB-treated skin after insertion
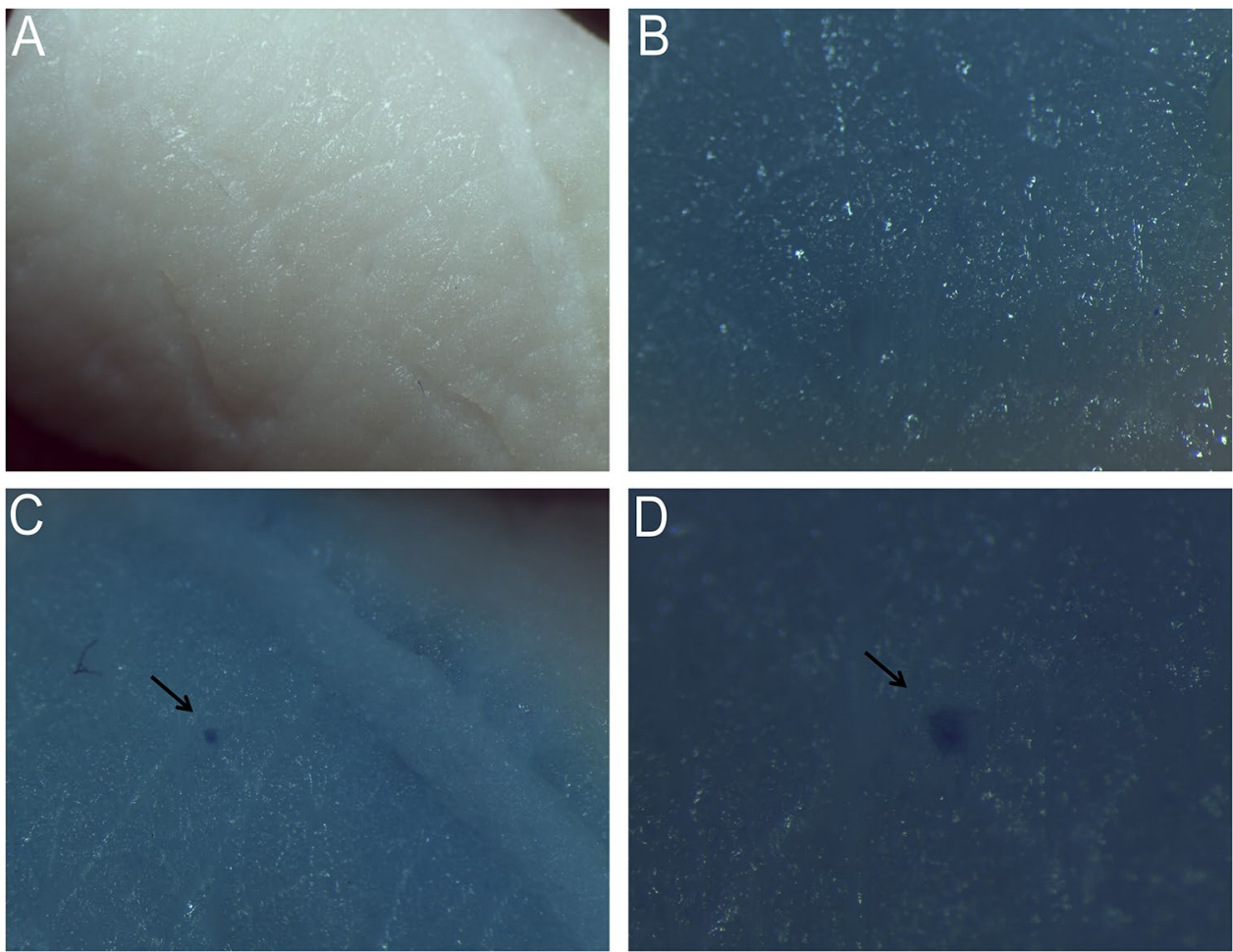

polymer microneedle was successfully inserted into skin piercing the stratum corneum.

\section{Microneedle release test into the in vitro dermis equivalent}

The in vitro dermis equivalent model was characterized by means of confocal microscopy. In particular, cell nuclei were stained and a 3D reconstruction of 2D confocal image stacks was recreated (Fig. 7b). The image shows that the cells are uniformly distributed throughout the collagen volume.

To test the collagenase release from a $\mathrm{MN}$ inside the in vitro dermis model, a microneedle was indented in the collagen and the enzyme fluorescence (i.e. the green signal) was followed overtime by means of confocal microscopy. In particular, three sampling times were chosen: $30 \mathrm{~min}, 2 \mathrm{~h}$ and $24 \mathrm{~h}$. At each time point the images of three slices of the $\mathrm{MN}$ (i.e. the $z$-positions corresponding to the MN base, half-height and tip) were acquired. (Fig. 7a). In more detail, the MN base view (first row of Fig. 7c-e) shows what is happening into the collagen in correspondence of the base of the needle, while the half-height view (second row of Fig. 7c-e) shows what is happening into the collagen at half height of the MN and the tip view (third row of Fig. 7c-e) shows what is happening into the collagen in correspondence of the microneedle tip. For each $z$-position the green channel (Fig. 7c-e(i)), the merged green and transmitted light (Fig. 7c-e(ii)) channels and the orthogonal projection (Fig. 7c-e(iii)) were acquired.
After 30 min from microneedle insertion inside the in vitro dermis model, the enzyme diffused from the porous microstructure of the needle only in correspondence of the base of the MN (Fig. 7c(i)-base), but not yet from the remaining length and from the tip (Fig. 7c(i)-half height and tip). The orthogonal projection shows the triangular profiles of the MN proving that its morphology is maintained at this time point (Fig. 7c(iii)).

After $2 \mathrm{~h}$, the protein started to diffuse towards the collagen of the dermis model even in correspondence of the half height of the MN (Fig. 7d(i)-base, half height and tip). The orthogonal projection still shows the triangular profiles of the MN proving that its morphology is maintained also at this time point (Fig. $7 \mathrm{~d}$ (iii)).

Finally, $24 \mathrm{~h}$ after microneedle insertion inside the model, the protein diffused out from the porous microstructure of the MN along its whole length (Fig. 7e(i)). Moreover, the tip is completely dissolved as shown in the orthogonal sections (Fig. 7e(iii)) where the triangular profile of the microneedle is not visible anymore, proving that, at this time point, its architecture is completely lost.

In addition, Fig. 8 shows the maximal projection of the $z$-stack of the microneedle at the considered time points. As it can be seen from the images, the diffusion wavefront of the protein increases when increasing the release time. In more detail, after $30 \mathrm{~min}$, a circular green signal of about $750 \mu \mathrm{m}$ in diameter is visible, so the wave-front is of about $150 \mu \mathrm{m}$ from the base. After $2 \mathrm{~h}$, the wave front is of about $295 \mu \mathrm{m}$. Finally, after $24 \mathrm{~h}$ the wave-front is of 
A
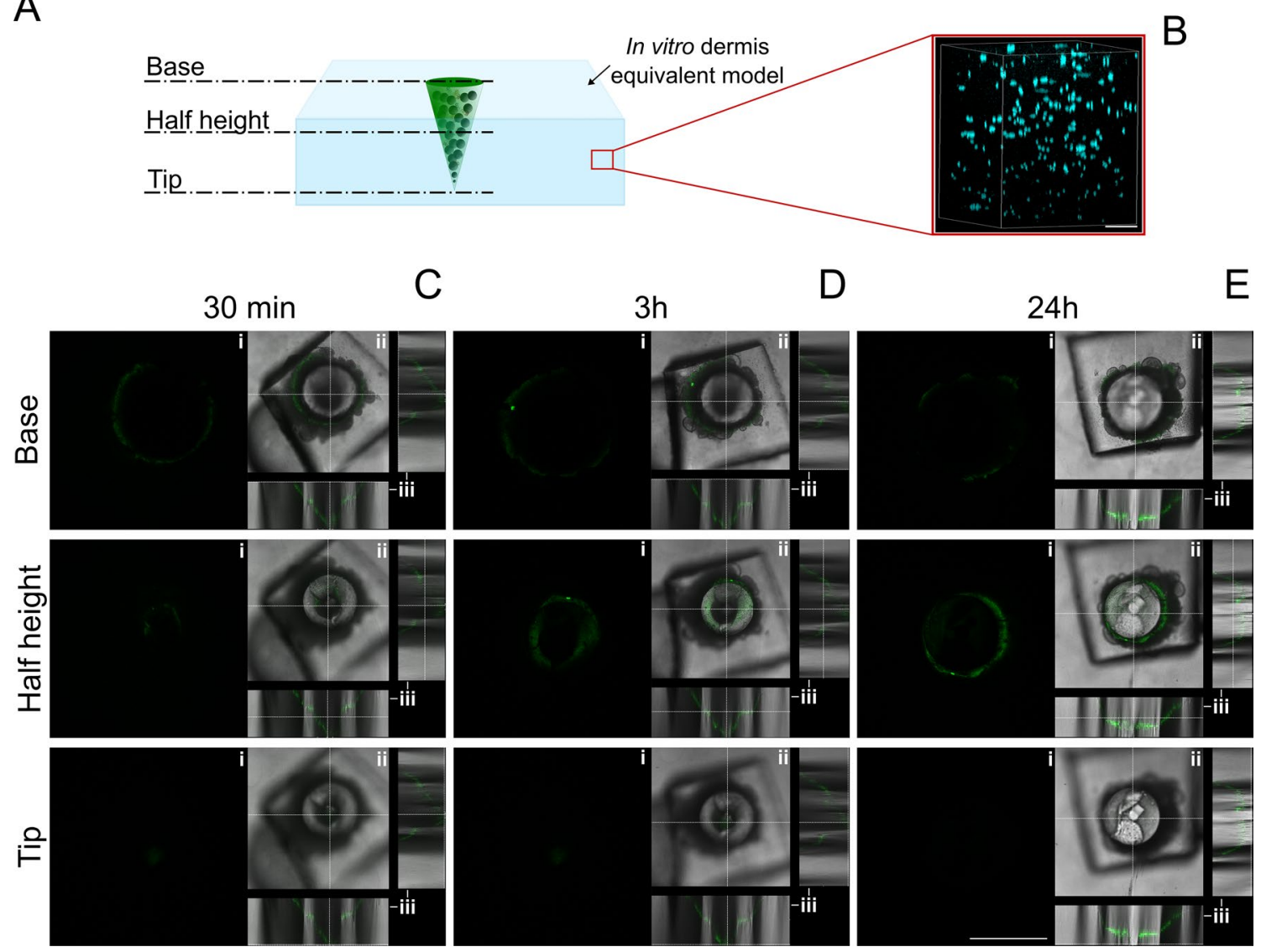

Fig. 7 a Images were acquired by confocal microscopy at z-positions corresponding to the base, the middle height and the tip of the microneedle. b 3D reconstruction of the in vitro skin equivalent by means of confocal microscopy; cells nuclei can be seen inlight blue.
Scale bar $100 \mu \mathrm{m}$. c Release test of the microneedle in the in vitro skin equivalent model after $30 \mathrm{~min}, 3 \mathrm{~h}, 24 \mathrm{~h}$ (top, middle and bottom views). Scale bar $600 \mu \mathrm{m}$

A

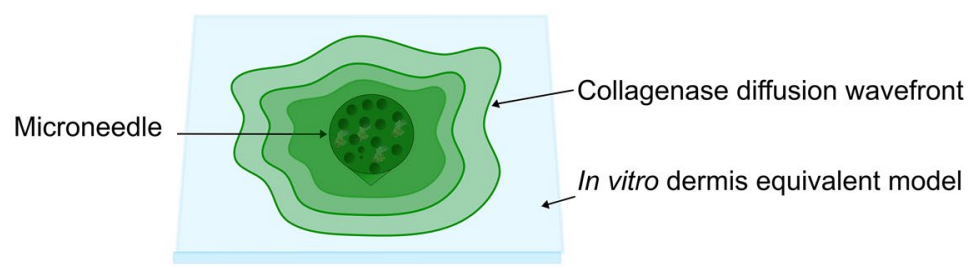

$30 \min$

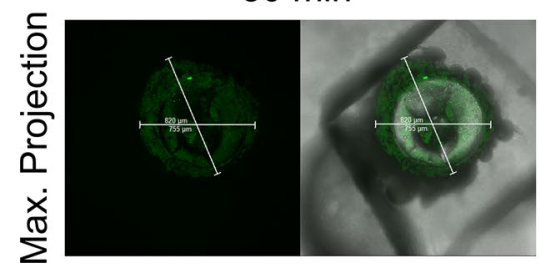

$3 h$

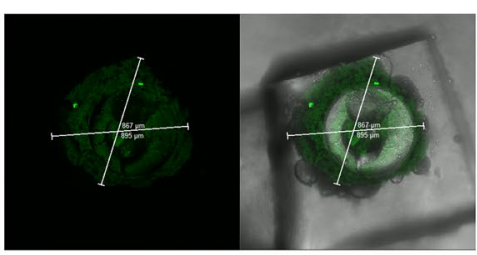

B

$24 \mathrm{~h}$

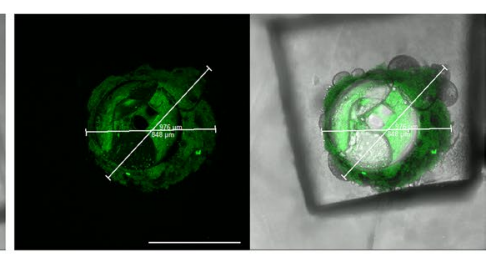

Fig. 8 a Schematic representation of the collagenase diffusion wave-front. b Collagenase diffusion wave-front from the microneedles after $30 \mathrm{~min}, 2 \mathrm{~h}, 24 \mathrm{~h}$. Scale bar $600 \mu \mathrm{m}$ 
about $376 \mu \mathrm{m}$. Moreover, especially after $24 \mathrm{~h}$, the inevitable signal attenuation due to the protein diffusion and dilution into the whole collagen volume has to be taken into account when observing the images.

\section{Discussion}

The use of simple MN based methods allows intradermal drug delivery through a minimally invasive strategy (Jamaledin et al. 2020; Park et al. 2019). Moreover, the employment of polymers which are well recognized as excipients in pharmaceutical formulations is known to preserve proteins from degradation, stabilizing the drug within the microneedle preparation (Zelikin et al. 2016).

Pharmaceutical agents can be embedded in polymeric microneedles fabricated using biodegradable polymers such as PLGA, for a sustained release, or water-soluble polymers as PVP, so that microneedles fast dissolve releasing their payload (Ita 2017).

In this work, novel biodegradable microneedles made up of PLGA together with a PVP copolymer, were designed, fabricated and analyzed to reach intermediate release rates of the encapsulated active pharmaceutical ingredient. Microneedles were produced with a stamp-less technique based on the electro-drawing principle. In a previous work on electro-drawn MNs (Vecchione et al. 2014), the electric field, able to promote the ED, was achieved by a punctual thermal stimulus to a pyroelectric crystal by means of a hot tip. Consequently, it was not possible to electro-draw microneedles in parallel and they presented a pedestal at their basis. To optimize the delivery of the drug embedded in the $\mathrm{MN}$, a double dispensing procedure was implemented according to which the drug was only present in the second top drop. In a more recent work (Ruggiero et al. 2018) as well as in this paper, a novel ED setup was optimized, based on the direct pattern of titanium spiral-shaped heaters onto the pyroelectric crystal surface, to control the generated electric field at the microscale, consequently obtaining a faster fabrication of the MNs. Here, for the first time the electro-drawing was applied to mixtures of PVP/VA and PLGA with the aim of obtaining faster release profiles as compared with pure PLGA.

Both PVP/VA and PLGA are Food and Drug Administration (FDA) approved polymers for in vivo administration, widely used as drug delivery carriers for microneedles (Ke et al. 2012; Schwarz, 1990; Stevanovic et al. 2011). PVP microneedles fast dissolve after insertion within the biological tissues due to the PVP high water solubility (Sullivan et al. 2008; Sun et al. 2013; Thakur et al. 2016). Its monomer $N$-vinyl pyrrolidone is able to copolymerize with acrylic acid, methacrylates and other vinyl monomers and the formed polymers are widely used in biomedical applications such as contact lenses (Lai 1997), fast and controlled delivery of drugs (Yaung and Kwei 1998), and for immobilization of the enzymes (Basri et al. 1999). Recently many swelling studies of PVP based hydrogels have been published, in which PVP has been blended with pectin to improve its mechanical properties (Bajpai 2000; Maolin et al. 2000; Mishra et al. 2008; Park and Nho 2003).

On the contrary, PLGA-based devices (Cabezas et al. 2014; Klose et al. 2008), as well as PLGA-based MNs (Li et al. 2019), require long time from several days to weeks to release drugs and thus are usually employed for sustained release. In particular, the drug release rates are influenced by factors such as polymer molecular weight, poly lactic acid (PLA)/poly glycolic acid (PGA) ratio (Makadia and Siegel 2011), the geometry of the devices, the drug type, and drug release medium (Klose et al. 2008). All these factors need to be considered to have the desired drug release mechanism. In detail, the PLGA degradation can be accelerated by increasing PLGA hydrophilicity and the chemical interactions among the hydrolytic groups or reducing the volume to surface ratio of the device (Makadia and Siegel 2011). For example, for drug releases up to one month, a polymer with high hydrophilicity is recommended, while for a longer-term release of several months, a PLGA with high molecular weight could be suitable (Houchin and Topp 2009). Furthermore, it has been well established that PLGA can encapsulate small molecules, peptides or proteins and distribute them with different periods of time and routes of delivery (Battisti et al. 2019; Fischer et al. 2009; Kim et al. 2013a, b).

To promote faster release rates, one strategy is to obtain porosity in PLGA matrices. For example porogen agents showed being a simple method and have been widely employed to realize pores (Clark et al. 2014; Ni et al. 2017; Ullah et al. 2017; Xu et al. 2017). Recently, trehalose was used as a porogen for the release of hydrophobic drugs from PLGA-based MNs (Zhao et al. 2020).

In our case, with the aim of increasing PLGA porosity, we fabricated microneedles starting from water-in-oil (W/O) emulsions containing lecithin, which is a surfactant, and maltose as emulsion stabilizer. Maltose was chosen because, being emulsions instable systems, they have the tendency of undergoing a phase-separation before consolidation (i.e. before starting the MN fabrication), especially for high concentrations of the dispersed phase. Recently, in the case of $\mathrm{W} / \mathrm{O}$ emulsions, the addition of maltose in the water phase has been proposed as an effective way to enhance stability (Esposito et al. 2016). On the other hand, maltose has been previously introduced in literature as effective material for the fabrication of dissolving drug delivery systems, such as microneedles (Lee et al. 2011).

The consolidation of the porous microstructure occurred through solvent evaporation from the continuous phase of 
the W/O emulsion. The sole PLGA in the oil phase, together with lecithin and maltose in the water phase, brought to the formation of big pores, but such pores had a closed morphology. The addition of PVP/VA in the oil phase allowed to obtain microneedles with an interconnected porosity, where the polymer chains of PVP, being PVP hydrophilic, were entrapped together with the drug (Browne et al. 2020). These microneedle microstructure and porosity are related to the amount of drug that can be loaded inside the polymeric matrix and to the MN release rate. The introduction of PVP/ VA allowed the formation of an interconnected porosity, increasing the protein release to the $27 \%$ in $3 \mathrm{~h}$ compared to the $6.5 \%$ of the sole PLGA.

Another method to control and eventually increase the release rates of pharmaceutical components embedded in PLGA matrix is to use PLGA microparticles (MPs) delivered by microneedle patches. In this way the release is characterized by an initial burst followed by a slight linear phase (Battisti et al. 2019; Mazzara et al. 2019). Even if it is not excluded that MPs could be introduced to fabricate multicompartmental microneedles by electro-drawing, one of the advantages of producing MNs starting from W/O emulsions is that the process is one step and thus very fast.

Moreover, a main advantage is that our process showed to work well with proteins without destroying their activity. Indeed, the ability to release drugs in a timeframe of few hours is compatible with labile molecules such as proteins like collagenase which otherwise, for longer release times, can start to degrade due to the wet environment surrounding the delivery system. It is reported that when the enzyme is in contact with water, for example in the case of reconstitution for injectable formulations, it has to be injected within $8 \mathrm{~h}$ to avoid degradation problems (Vaccaro et al. 2017). At the same time, this time-frame is advantageous as compared to an immediate release where protein is immediately exposed to the degrading biologic environment and part of it may be degraded before acting (Chi et al. 2003; Volkin and Klibanov 1989; Zhu et al. 2000). In addition, maintaining high systemic but non-toxic drug exposures may be useful to preserve a sufficient molecule activity in vivo, when degradation mechanisms start (Lai and Crews 2017; Shire et al. 2004).

For this reason, we think that the obtained materials could be used for the delivery of a broader spectrum of labile molecules such as antibodies, peptides or small biomolecules.

\section{Conclusion}

This work presents fast degradable porous microneedles obtained with a stamp-less electro-drawing based approach. Electro-drawing is a fast, mold-free, one-step, mild temperature and easily tunable drug delivery strategy that overcomes the technological limitations of both micromolding and drawing lithography. However, the formulations used so far in ED microneedles are PLGA-based with long release times, which are not compatible with labile biomolecules. In this work, ED microneedles were drawn starting from water-in-oil (W/O) emulsion drops and a drug with full-blown dermo-cosmetic activities, such as collagenase, was embedded in the microcavities created within the polymeric phase. In this regard, being the inner microneedle structure related to the drug release, we studied different possible water-in-oil precursor formulations to tune pore morphology and collagenase release profiles to obtain protein releases in an active form and in a time-frame of few hours. This was possible by replacing PLGA with a polymeric matrix made of poly(lactic-co-glycolic acid)(PLGA) with Poly(1-vinylpyrrolidone-co-vinyl acetate) (PVP/VA) to accelerate degradation and using a water-in-oil emulsion to provide a porous matrix. The resulting microneedles were able to pierce the stratum corneum of cadaver porcine skin and collagenase was able to diffuse in a controlled manner over the time in a 3D in vitro dermis model.

These findings could have significant implications for the development of new cosmetic applications as well as for skin disease therapies.

Acknowledgements The authors thank Dr. Fabio Formiggini for technical assistance in the acquisition of confocal images and Dr. Valentina Mollo for the realization of microneedle slices and her assistance in the acquisition of SEM images. The authors thank Rezvan Jamaledin for her help in the use of the electro-drawing set-up and Elena Lagreca for her assistance in the collagenase-related experiments. The authors thank Fidia Farmaceutici S.p.A for having supported the research, authorship and publication of this article.

Author contributions Valentina Onesto prepared the W/O emulsions, fabricated the integrated device, the microneedles, did the morphological analysis of the microneedles and helped in all the other experiments. She even wrote the original draft of the manuscript. Concetta Di Natale functionalized the Collagenase, did the entrapment efficiency, release and activity experiments and wrote the corresponding sections of the manuscript. Martina Profeta did the mechanical failure test, insertion assessment into cadaver pig skin, release test in the in vitro dermis model and wrote the corresponding sections of the manuscript. Raffaele Vecchione and Paolo Netti conceived the idea and the design of the material and commented on results. All the authors commented on the manuscript.

Funding Open access funding provided by Istituto Italiano di Tecnologia within the CRUI-CARE Agreement. This work was supported by Fidia Farmaceutici S.p.A,via Ponte della Fabbrica 3/A-35031 Abano Terme (PD), Italy.

\section{Compliance with ethical standards}

Conflict of interest The authors declare no conflict of interest.

Open Access This article is licensed under a Creative Commons Attribution 4.0 International License, which permits use, sharing, adaptation, distribution and reproduction in any medium or format, as long 
as you give appropriate credit to the original author(s) and the source, provide a link to the Creative Commons licence, and indicate if changes were made. The images or other third party material in this article are included in the article's Creative Commons licence, unless indicated otherwise in a credit line to the material. If material is not included in the article's Creative Commons licence and your intended use is not permitted by statutory regulation or exceeds the permitted use, you will need to obtain permission directly from the copyright holder. To view a copy of this licence, visit http://creativecommons.org/licenses/by/4.0/.

\section{References}

Badalamente MA, Hurst LC (2007) Efficacy and safety of injectable mixed collagenase subtypes in the treatment of Dupuytren's contracture. J Hand Surg Am 32:767-774

Bajpai SK (2000) Poly (N-vinyl-2-pyrrolidone)-polyacrylamide hydrogels as extraction solvents. Iranian Polym J 9(1):19-27

Balmayor ER, Azevedo HS, Reis RL (2011) Controlled delivery systems: from pharmaceuticals to cells and genes. Pharm Res 28:1241-1258

Bariya SH, Gohel MC, Mehta TA, Sharma OP (2012) Microneedles: an emerging transdermal drug delivery system. J Pharm Pharmacol 64:11-29

Basri M, Wong CC, Ahmad MB, Razak CNA, Salleh AB (1999) Immobilization of lipase on poly (N-vinyl-2-pyrrolidone-co-2-hydroxyethyl methacrylate) hydrogel for the synthesis of butyl oleate. J Am Oil Chem Soc 76:571-577

Battisti M, Vecchione R, Casale C, Pennacchio FA, Lettera V, Jamaledin R, Profeta M, Di Natale C, Imparato G, Urciuolo F (2019) Non-invasive production of multi-compartmental biodegradable polymer microneedles for controlled intradermal drug release of labile molecules. Front Bioeng Biotechnol 2019:7

Bediz B, Korkmaz E, Khilwani R, Donahue C, Erdos G, Falo LD, Ozdoganlar OB (2014) Dissolvable microneedle arrays for intradermal delivery of biologics: fabrication and application. Pharm Res 31:117-135

Browne E, Worku ZA, Healy AM (2020) Physicochemical properties of poly-vinyl polymers and their influence on ketoprofen amorphous solid dispersion performance: a polymer selection case study. Pharmaceutics 12:433

Cabezas LI, Gracia I, de Lucas A, Rodríguez JF (2014) Validation of a mathematical model for the description of hydrophilic and hydrophobic drug delivery from biodegradable foams: experimental and comparison using indomethacin as released drug. Ind Eng Chem Res 53:8866-8873

Chi EY, Krishnan S, Randolph TW, Carpenter JF (2003) Physical stability of proteins in aqueous solution: mechanism and driving forces in nonnative protein aggregation. Pharm Res 20:1325-1336

Clark A, Milbrandt TA, Hilt JZ, Puleo DA (2014) Mechanical properties and dual drug delivery application of poly (lactic-co-glycolic acid) scaffolds fabricated with a poly ( $\beta$-amino ester) porogen. Acta Biomater 10:2125-2132

Di Natale C, Onesto V, Lagreca E, Vecchione R, Netti PA (2020) Tunable release of curcumin with an in silico-supported approach from mixtures of highly porous PLGA microparticles. Mater (Basel) 13:1807

Di Pasquale R, Vaccaro S, Caputo M, Cuppari C, Caruso S, Catania A, Messina L (2019) Collagenase-assisted wound bed preparation: an in vitro comparison between Vibrio alginolyticus and Clostridium histolyticum collagenases on substrate specificity. Int Wound J 16:1013-1023

Esposito E, Ruggiero F, Vecchione R, Netti P (2016) Room temperature consolidation of a porous poly (lactic-co-glycolic acid) matrix by the addition of maltose to the water-in-oil emulsion. Mater (Basel) 9:420

Fischer S, Schlosser E, Mueller M, Csaba N, Merkle HP, Groettrup M, Gander B (2009) Concomitant delivery of a CTL-restricted peptide antigen and CpG ODN by PLGA microparticles induces cellular immune response. J Drug Target 17:652-661

Franco P, De Marco I (2020) The use of poly (N-vinyl pyrrolidone) in the delivery of drugs: a review. Polym (Basel) 12:1114

Hermanson GT (2013) Bioconjugate techniques. Academic press, Cambridge

Houchin ML, Topp EM (2009) Physical properties of PLGA films during polymer degradation. J Appl Polym Sci 114:2848-2854

Ita K (2017) Dissolving microneedles for transdermal drug delivery: advances and challenges. Biomed Pharmacother 93:1116-1127

Jamaledin R, Di Natale C, Onesto V, Taraghdari ZB, Zare EN, Makvandi P, Vecchione R, Netti PA (2020) Progress in microneedlemediated protein delivery. J Clin Med 9:542

Kamaly N, Yameen B, Wu J, Farokhzad OC (2016) Degradable controlled-release polymers and polymeric nanoparticles: mechanisms of controlling drug release. Chem Rev 116:2602-2663

Ke C-J, Lin Y-J, Hu Y-C, Chiang W-L, Chen K-J, Yang W-C, Liu H-L, Fu C-C, Sung H-W (2012) Multidrug release based on microneedle arrays filled with $\mathrm{pH}$-responsive PLGA hollow microspheres. Biomaterials 33:5156-5165

Kim Y-C, Park J-H, Prausnitz MR (2012) Microneedles for drug and vaccine delivery. Adv Drug Deliv Rev 64:1547-1568

Kim I, Byeon HJ, Kim TH, Lee ES, Oh KT, Shin BS, Lee KC, Youn YS (2013) Doxorubicin-loaded porous PLGA microparticles with surface attached TRAIL for the inhalation treatment of metastatic lung cancer. Biomaterials 34:6444-6453

Kim JD, Kim M, Yang H, Lee K, Jung H (2013) Droplet-born air blowing: Novel dissolving microneedle fabrication. J Control Release 170:430-436. https://doi.org/10.1016/j.jconr el.2013.05.026

Kim M, Yang H, Kim S, Lee C, Jung H (2015) The troy microneedle: a rapidly separating, dissolving microneedle formed by cyclic contact and drying on the pillar (CCDP). PLoS ONE 2015:10. https ://doi.org/10.1371/journal.pone.0136513

Klose D, Siepmann F, Elkharraz K, Siepmann J (2008) PLGA-based drug delivery systems: importance of the type of drug and device geometry. Int J Pharm 354:95-103

Lai Y (1997) Effect of crosslinkers on photocopolymerization of $\mathrm{N}$-vinylpyrrolidone and methacrylates to give hydrogels. J Appl Polym Sci 66:1475-1484

Lai AC, Crews CM (2017) Induced protein degradation: an emerging drug discovery paradigm. Nat Rev Drug Discov 16:101-114

Lee K, Jung H (2012) Drawing lithography for microneedles: a review of fundamentals and biomedical applications. Biomaterials 33:7309-7326

Lee JW, Park JH, Prausnitz MR (2008) Dissolving microneedles for transdermal drug delivery. Biomaterials 29:2113-2124. https:// doi.org/10.1016/j.biomaterials.2007.12.048

Lee K, Kim JD, Lee CY, Her S, Jung H (2011) A high-capacity, hybrid electro-microneedle for in-situ cutaneous gene transfer. Biomaterials 32:7705-7710. https://doi.org/10.1016/j.biomateria 1s.2011.06.058

Leone M, Monkare J, Bouwstra J, Kersten G (2017) Dissolving microneedle patches for dermal vaccination. Pharm Res 34:22232240. https://doi.org/10.1007/s11095-017-2223-2

Li W, Terry RN, Tang J, Feng MR, Schwendeman SP, Prausnitz MR (2019) Rapidly separable microneedle patch for the sustained release of a contraceptive. Nat Biomed Eng 3:220

Ma X, Oyamada S, Wu T, Robich MP, Wu H, Wang X, Buchholz B, McCarthy S, Bianchi CF, Sellke FW (2011) In vitro and in vivo degradation of poly (D, L-lactide-co-glycolide)/amorphous 
calcium phosphate copolymer coated on metal stents. J Biomed Mater Res Part A 96:632-638

Makadia HK, Siegel SJ (2011) Poly (lactic-co-glycolic acid) (PLGA) as biodegradable controlled drug delivery carrier. Polymers (Basel) 3:1377-1397

Malik T, Razzaq H, Razzaque S, Nawaz H, Siddiqa A, Siddiq M, Qaisar S (2019) Design and synthesis of polymeric membranes using water-soluble pore formers: an overview. Polym Bull 76:4879-4901

Maolin Z, Hongfei H, Yoshii F, Makuuchi K (2000) Effect of kappacarrageenan on the properties of poly (N-vinyl pyrrolidone)/ kappa-carrageenan blend hydrogel synthesized by $\gamma$-radiation technology. Radiat Phys Chem 57:459-464

Mazzara JM, Ochyl LJ, Hong JKY, Moon JJ, Prausnitz MR, Schwendeman SP (2019) Self-healing encapsulation and controlled release of vaccine antigens from PLGA microparticles delivered by microneedle patches. Bioeng Transl Med 4:116-128

McCall RL, Sirianni RW (2013) PLGA nanoparticles formed by single-or double-emulsion with vitamin E-TPGS. JoVE J Vis Exp 2013:51015

Hyalo4® Regen Verbandgaas is a pharmaceutical product (https:// www.pharmaclic.be/media/catalog/product/file/3412426-nl.pdf): MET, VULHETWO (2019), Hyalo4® Regen Verbandgaas

Mishra RK, Datt M, Banthia AK (2008) Synthesis and characterization of pectin/PVP hydrogel membranes for drug delivery system. Aaps Pharmscitech 9:395-403

Nejad HR, Sadeqi A, Kiaee G, Sonkusale S (2018) Low-cost and cleanroom-free fabrication of microneedles. Microsyst Nanoeng 4:17073

Nguyen HX, Bozorg BD, Kim Y, Wieber A, Birk G, Lubda D, Banga AK (2018) Poly (vinyl alcohol) microneedles: fabrication, characterization, and application for transdermal drug delivery of doxorubicin. Eur J Pharm Biopharm 129:88-103

Ni R, Muenster U, Zhao J, Zhang L, Becker-Pelster E-M, Rosenbruch M, Mao S (2017) Exploring polyvinylpyrrolidone in the engineering of large porous PLGA microparticles via single emulsion method with tunable sustained release in the lung: in vitro and in vivo characterization. J Control Release 249:11-22

Park KR, Nho YC (2003) Synthesis of PVA/PVP hydrogels having two-layer by radiation and their physical properties. Radiat Phys Chem 67:361-365

Park JH, Allen MG, Prausnitz MR (2005) Biodegradable polymer microneedles: fabrication, mechanics and transdermal drug delivery. J Control Release 104:51-66. https://doi.org/10.1016/j.jconr el.2005.02.002

Park J-H, Allen MG, Prausnitz MR (2006) Polymer microneedles for controlled-release drug delivery. Pharm Res 23:1008-1019

Park SC, Kim MJ, Baek S-K, Park J-H, Choi S-O (2019) Spray-formed layered polymer microneedles for controlled biphasic drug delivery. Polym (Basel) 11:369

Prudic A, Kleetz T, Korf M, Ji Y, Sadowski G (2014) Influence of copolymer composition on the phase behavior of solid dispersions. Mol Pharm 11:4189-4198

Ruggiero F, Vecchione R, Bhowmick S, Coppola G, Coppola S, Esposito E, Lettera V, Ferraro P, Netti PA (2018) Electro-drawn polymer microneedle arrays with controlled shape and dimension. Sensors Actuators B Chem 255:1553-1560

Schwarz W (1990) PVP: a critical review of the kinetics and toxicology of polyvinylpyrrolidone (povidone). CRC Press, Hoboken

Shire SJ, Shahrokh Z, Liu JUN (2004) Challenges in the development of high protein concentration formulations. J Pharm Sci 93:1390-1402
Stevanovic M, Pavlovic V, Petkovic J, Filipic M, Uskokovic D (2011) ROS-inducing potential, influence of different porogens and in vitro degradation of poly (D, L-lactide-co-glycolide)-based material. Express Polym Lett 5:996-1008

Sullivan SP, Murthy N, Prausnitz MR (2008) Minimally invasive protein delivery with rapidly dissolving polymer microneedles. Adv Mater 20:933. https://doi.org/10.1002/adma.200701205

Sun W, Araci Z, Inayathullah M, Manickam S, Zhang X, Bruce MA, Marinkovich MP, Lane AT, Milla C, Rajadas J (2013) Polyvinylpyrrolidone microneedles enable delivery of intact proteins for diagnostic and therapeutic applications. Acta Biomater 9:7767-7774

Thakur RRS, Tekko IA, Al-Shammari F, Ali AA, McCarthy H, Donnelly RF (2016) Rapidly dissolving polymeric microneedles for minimally invasive intraocular drug delivery. Drug Deliv Transl Res 6:800-815

Ullah A, Kim CM, Kim GM (2017) Solvent effects on the porosity and size of porous PLGA microspheres using gelatin and PBS as porogens in a microfluidic flow-focusing device. J Nanosci Nanotechnol 17:7775-7782

Vaccaro S, Caputo M, Cuppari C, Gennari G (2017) New process for the production and purification of the collagenase enzyme from vibrio alginolyticus, US Patent, US20170314005A1

Vecchione R, Coppola S, Esposito E, Casale C, Vespini V, Grilli S, Ferraro P, Netti PA (2014) Electro-drawn drug-loaded biodegradable polymer microneedles as a viable route to hypodermic injection. Adv Funct Mater 24:3515-3523. https://doi.org/10.1002/ adfm.201303679

Volkin DB, Klibanov AM, Creighton TE (1989) Protein function: a practical approach. Oxford Inf Press 1:24

Wu F, Jin T (2008) Polymer-based sustained-release dosage forms for protein drugs, challenges, and recent advances. Aaps Pharmscitech 9:1218-1229

Wuensch E, Heidrich HG (1963) On the quantitative determination of collagenase. Hoppe Seylers Z Physiol Chem 333:149-151

Xu Y, Kim C, Saylor DM, Koo D (2017) Polymer degradation and drug delivery in PLGA-based drug-polymer applications: a review of experiments and theories. J Biomed Mater Res Part B Appl Biomater 105:1692-1716

Yaung J, Kwei TK (1998) pH-sensitive hydrogels based on polyvinylpyrrolidone-polyacrylic acid (PVP-PAA) semi-interpenetrating networks (semi-IPN): Swelling and controlled release. J Appl Polym Sci 69:921-930

Zelikin AN, Ehrhardt C, Healy AM (2016) Materials and methods for delivery of biological drugs. Nat Chem 8:997

Zhao X, Zhang S, Yang G, Zhou Z, Gao Y (2020) Exploring Trehalose on the release of levonorgestrel from implantable PLGA microneedles. Polym (Basel) 12:59

Zhu G, Mallery SR, Schwendeman SP (2000) Stabilization of proteins encapsulated in injectable poly (lactide-co-glycolide). Nat Biotechnol 18:52-57

Publisher's Note Springer Nature remains neutral with regard to jurisdictional claims in published maps and institutional affiliations. 